\title{
PERCURSOS DAS SOCIEDADES QUE LEVARAM À INDIFERENÇA HUMANA
}

\author{
SOME PATHS OF THE SOCIETIES THAT LED \\ TO INDIFFERENCE FOR HUMAN
}

\author{
PERCURSOS DE LAS SOCIEDADES QUE \\ LEVARAM À INDIFERENÇA HUMANA
}

\author{
Elaine Conte ${ }^{\mathrm{I}}$ \\ Maiane Hastchbach Ourique ${ }^{I I}$
}

\begin{abstract}
Resumo $\mathrm{O}$ ensaio mapeia os percursos das sociedades que levaram à indiferença com o outro como indício paradoxal mais visível de que a formação humana sofre efeitos de desencantamento do mundo. $\mathrm{O}$ aprender a conviver democraticamente aparece ameaçado por tentativas de desvalorização ou negação do outro. A indiferença como manifestação de barbárie indica que elos com a historicidade humana foram rompidos e põem em alerta os processos de formação. Diante disso, pergunta-se: em que sentido a formação pode reconstruir laços de responsabilidade com o mundo e com a vida, minimizando os efeitos gerados pela negligência e embrutecimento do humano? Se a diferença revela uma condição humana, a indiferença é a marca de quem não consegue mais se descentrar e se relacionar com a cultura. O enfrentamento dessa problemática acontece tanto no âmbito jurídico, preservando as condições de igualdade e respeito pela singularidade, quanto formativo, revitalizando os sentidos de nossa presença no mundo e reconstruindo formas de pertencimento e implicação com a alteridade.

Palavras-chave: Indiferença; Outro; Reconhecimento; Formação.
\end{abstract}

Abstract The essay map to point out some paths of the societies that led to indifference to the other as paradoxical evidence more visible from which the human formation still suffers effects of barbarism. The learning of living democratically appears threatened by attempts to devaluation or negation of the other. Indifference as barbaric manifestation

Universidade La Salle (UNILASALLLE), Canoas/RS

II Universidade Federal do Pampa (UNIPAMPA), Bagé/RS 
indicates, among other things, that links to human historicity were broken and put on alert the processes of human. Therefore, we ask: in what way the training can rebuild responsibility of ties with the world and with life, thus minimizing the effects generated by human negligence and brutalization? If the difference reveals a condition of the human, indifference is the mark of a time that no longer recognizes its responsibility to the world, relating with a sterile way with culture. The confrontation of this problem takes place both in the juridical sphere, preserving the conditions of equality and respect for singularity, as well as formative, revitalizing the senses of our presence in the world and reconstructing forms of belonging and implication with otherness.

KeY-WORDS: INDIFFERENCE; Other; ReCOGNITION; FoRMATION.

Resumen El ensayo tiene por objeto señalar algunos caminos de sociedades plurales que llevaron a la indiferencia con el otro como indicación más visible del paradójico de que la formación humana aún sufre los efectos de la barbarie y el olvido. El aprender a convivir democráticamente aparece amenazado por los intentos de devaluación o la negación del otro. La indiferencia como manifestación de barbarie indica, entre otras cosas, que os enlaces con la historicidad humana estaban rotas y puso en alerta a los procesos de desarrollo humano (Bildung). Por lo tanto, nos preguntamos: ¿de qué sentido la formación puede reconstruir la responsabilidad de las relaciones con el mundo y con la vida, minimizando así los efectos generados por la negligencia humana y brutalización? Si la diferencia revela una condición humana, la indiferencia es la marca de un tiempo que ya no reconoce su responsabilidad en el mundo, en relación estéril con la cultura. Para abordar este problema se produce tanto en el marco legal, el mantenimiento de las condiciones de igualdad y el respeto por la singularidad, la formación, la revitalización de los sentidos de nuestra presencia en el mundo y la reconstrucción de las formas de pertenencia y participación con la alteridad.

Palabras claves: Indiferencia; Otro; Reconocimiento; Formación.

\section{INTRODUZINDO O DEBATE}

O ensaio tem a intenção de assinalar alguns percursos das sociedades plurais que levaram à indiferença com o outro, como indício paradoxal mais visível de que a formação humana ainda sofre efeitos de barbárie e esquecimento. O processo que nos torna humanos envolve a aceitação da nossa corporeidade, a interação e o estímulo às forças criativas próprias. Ou seja, compreende a imprescindível presença do outro na busca por reconhecimento, o que nos aproxima e, ao mesmo tempo, inquieta e nos projeta à ação, mostrando inclusive os limites de nossa visão de mundo. Nesse sentido, viver eticamente ${ }^{1}$ é renunciar à atitude de dominação dos outros para estar junto e conviver de forma responsável e solidária como base ao entendimento rico em possibilidades de relações materializadas na

1 "Ética é, assim, o fundamento da condição humana que vive e medita sobre si, sobre seu lugar, sobre sua casa, sobre seu mundo. [...] Ética é o fundamento de todas as especificidades do viver, em suas mais complexas relações e derivações, das ciências e da tecnologia, da história das comunidades e da própria filosofia" (SOUZA, 2009, p. 144). 
linguagem. É com essa perspectiva de abertura dos sujeitos ao mundo da vida - permeado por saber, cultura, linguagem, história, formação - que surge a relação integradora e vivificante do movimento, capaz de produzir a sensibilidade diante da presença do outro. Por um lado, sabemos que o fato de ser escutado, acolhido, compreendido e questionado pelo outro guarda condições de possibilidade para romper com a tendência monológica e estabelecer uma relação dialógica intersubjetiva, como um dispositivo imprescindível para a compreensão e a produção do conhecimento na infinita diversidade. Por outro, nossa época continua a produzir a indiferença e a desigualdade como se fossem fenômenos próprios de um modelo de evolução social, chegando a ponto de o século XX ter recebido a conhecida denominação de "século sangrento", ${ }^{2}$ estendido, talvez, também para o século XXI.

É no movimento mediado pelo outro ${ }^{3}$ que aprendemos e nos transformamos com a complexidade da vida, seja por nossa própria vontade, seja impulsionados pela dor e indignação. Tal compreensão aponta que as relações sociais no sentido amplo são constituídas pelas contradições e transformações intersubjetivas no processo do devir histórico em sociedade. Para que todas as pessoas possam contribuir para o intercâmbio que reanima as discussões éticas no constituir-se com a reivindicação do outro:

Cabe ainda registrar que a experiência do outro está vinculada à história de sua apropriação, e uma das formas mais expressivas dessa apropriação na tradição ocidental se refere ao egocentrismo, que reduz o estranho ao próprio, àquilo que é comum. O que não se articula pela razão tende a ser desvalorizado e até excluído. Trata-se de um individualismo exacerbado, possessivo, uma atomização do mundo, em que a luta de cada um pela autopreservação determina aquilo que se interpõe a tal processo como barreira e como estranho (HERMANN, 2014, p. 482).

O aprender a conviver democraticamente aparece ameaçado por tentativas de desvalorização ou negação do outro. Nestes tempos de grandes avanços da racionalidade e de conquistas importantes para a ação humana - mapeamento do genoma humano, construção

2 Difundida inicialmente nos países da Europa e Ásia, a expressão é cunhada a partir dos intensos conflitos e massacres ocorridos ao longo do século XX, como as duas Grandes Guerras e os combates do Vietnã e do Golfo. Para Negt \& Kluge (1999), esses acontecimentos influenciaram sobremaneira o espaço público e o debate das ideias, mesmo que sua complexidade e opacidade ainda estejam presentes nas formas de elaboração dos conceitos, de compreensão da realidade e de reconhecimento público: "Não é possível ter uma visão clara das zonas de conflito, pois nenhuma ideia, nenhum conceito-chave deste século sangrento ficou incólume: nem a liberdade nem a democracia, nem a comunidade e o povo, nem o Estado, nem o capitalismo e tampouco o socialismo. Uma vez que todos esses conceitos e ideias perderam sua inocência moral, é constrangedor observar no atual processo de autodesmitificação dos conceitos de resistência, utopia e protesto obstinado que, com o crescimento esmagador da realidade da linguagem política dos vencedores, as possibilidades de expressão dos vencidos são destruídas por um tempo indeterminado" (NEGT; KLUGE, 1999, p. 64-65).

3 A dimensão da palavra "outro" provém do latim alteritas, alteridade, diversidade, que significa novas compreensões do outro no trabalho de identificação (identidade, singularidade, autoconsciência, ipseidade) e diferenciação (diferença, estranhamento). Daí que a identidade de cada sujeito se faz sempre na presença de seu outro, enquanto plasticidade posta em movimento pelas interações. A alteridade se define pela construção de uma identidade e vice-versa. 
do grande colisor de partículas Hádrons para reproduzir as condições do Big-Bang, acessibilidade à tecnologia digital, descobertas que prolongam a vida etc. -, temos presenciado ainda manifestações de agressão e violência contra a humanidade. Barbáries e catástrofes provocadas pelo próprio homem indicam que elos com a historicidade humana foram rompidos e põem em alerta os processos de formação humana (Bildung). Diante da desigualdade e da indiferença com o outro, em que sentido a formação pode reconstruir laços de responsabilidade com o mundo e com a vida, minimizando, assim, os efeitos gerados pela negligência e embrutecimento do humano? Que posicionamentos éticos podemos tomar para reprimir ações geradoras de indiferença e barbárie? Segundo Todorov (2000), tanto o totalitarismo - que destrói documentos e monumentos, agenciando as informações aos seus propósitos - quanto o democratismo - que negligencia a História e os acontecimentos, hiperbolizando as informações - são geradores de barbárie e esquecimento. Por isso, levantamos aqui a hipótese de que, no contemporâneo, os processos formativos não se justificam mais no sentido de uma reação capaz de reconstituir a unidade da História, mas na assunção de uma postura crítica e comprometida com a memória, que retira dos acontecimentos históricos seu caráter factual ou uniforme para dotá-los de tons multifacetados.

A apropriação ingênua e abstrata do mundo cria expectativas niveladoras e dificuldades de interação que desestabiliza a experiência no mundo, porque desconsidera o movimento de abertura dialética para com o outro. E isso quer dizer que, "em todos os momentos de nossa vida, define-se em cada situação a continuidade de nossa existência, não através de atos indiferentes, mas na especificidade única e não-neutra de cada ato" (SOUZA, 2009, p. 144). Toda ação humana não é neutra ou indiferente à vida, mas pode tanto promover a criação vital e ser entrelaçada no processo de ensinar e aprender como pode conspirar para a sua fragilização ou objetividade distanciada, em termos de exclusões e violências. Evidentemente, a fronteira que desperta o outro está relacionada ao que percebemos e reconhecemos nas diferentes vozes da racionalidade, na multiplicidade dos outros, que implica imediatamente a capacidade de descentramento do pensar e do agir para apreender o mundo (HABERMAS, 2002). Caso não fosse assim, seríamos uma razão onisciente e não precisaríamos aprender nada com o outro.

Para que aconteça o diálogo que promove o entendimento humano, é necessária a presença do outro, que pressupõe relações humanas na finitude da linguagem e na dinâmica de confrontar diferentes visões de mundo como possibilidade de colocar-se no lugar do outro (GADAMER, 1999). A questão da identidade e do reconhecimento do outro na constituição cultural pode ser relacionada com a linguagem, o tempo e a confrontação com o outro, no acoplamento constitutivo. Pertence à dialética da constituição humana o processo originário da linguagem que motiva o compreender humano e atesta a nossa finitude (GADAMER, 1999). Afinal, a condição humana enquanto ação é construção histórica, não uma conformidade a ambientes estáticos e estéreis, pois depende da experiência como um processo que articula sentidos na palavra, a partir das necessidades e exigências próprias da vida, de novas relações éticas, políticas e econômicas na sociedade (ARENDT, 1999).

As ações humanas têm a ver tanto com o que sentimos, quanto com as deliberações 
que tomamos e as escolhas que fazemos. Em sua origem, elas guardam uma dimensão ético-estética que constitui a própria humanidade do humano. Mas o que significa falar em reconhecimento e formação numa sociedade que insiste na mercantilização, ${ }^{4}$ violação crescente da vida e da trama das relações sociais como serviços ou como bens de consumo? O que é intrinsecamente humano e o que nos torna desumanos e hostis ao outro?

\section{A IndiferenÇa EnQuanto ESQUeCimento ético}

A indiferença enquanto violência é um fenômeno complexo e polissêmico que tem suas raízes no agir desumano, enquanto barreira dos opostos, das diferenças e do diálogo intersubjetivo. Toda ação linguística é seletiva, porque é contada sempre de modo diferente e mostra apenas os momentos notáveis da ação que permitem a encenação dos eventos narrados e dos personagens da ação (RICOEUR, 2000). Daí que tanto abre oportunidade à distorção estratégica dos fatos por relações de poder (exploração ideológica), quanto serve à crítica da manipulação do esquecimento (falibilidade da memória) ou da rememoração. A indiferença compreende ações que geram humilhação, vergonha, discriminação, entre outras condutas violentas. O jargão do "bode expiatório", por exemplo, ilustra bem a interpretação de uma cultura da contradição, que busca a saída de situações de conflito, resultando na reconciliação (acessibilidade) de todos contra um (irrecuperável) e criando áreas de indiferença, onde o que é irrelevante (fora do padrão) é posto.

A existência de conflitos não se confunde com a violência, mas estes se tornam violentos no momento em que perdem a possibilidade de serem trabalhados e resolvidos politicamente e se convertem em enfrentamento de forças. Os conflitos constituem também as narrativas históricas e possuem condições de possibilidade de promover aprendizagens e formação. Nesse sentido, uma sociedade que não promove mediações e questionamentos diante de conflitos rompe com os processos de socialização cultural e reconhece a indiferença e a segregação como processos legítimos. Essa insensibilidade, derivada do medo, de preconceitos delirantes, da irracionalidade, é promovida e legitimada de diferentes formas nas relações interpessoais, tanto por sujeitos e facções organizadas, quanto por instituições que agem mediante a violência estrutural e mercadológica.

Segundo Cohn (2004, p. 85), a face contemporânea da barbárie expressa-se na indiferença, entendida como "a aceitação generalizada da diferença". Acrescenta ainda: "Claro que somos de fato diferentes. Nisso reside o momento de verdade da barbárie. A sua falsidade consiste precisamente em tornar absoluto esse seu momento de verdade. (Todo relativismo repousa em algum absoluto não questionado)" (COHN, 2004, p. 85). Se a diferença

4 Cabe destacar que os três mercados mais vendáveis no mundo são, respectivamente, seres humanos, drogas e armas. O questionamento das civilizações está justamente no fato de que elas produzem uma anticivilização, manifestada nos mecanismos da barbárie (ADORNO, 2000). Uma perspectiva cinematográfica sobre a vulnerabilidade humana é retratada no filme "Quanto vale ou é por quilo?", que apresenta uma analogia entre o antigo comércio de escravos e a atual exploração da miséria pelo marketing social, que forma uma solidariedade de fachada. 
revela a condição da pluralidade humana em termos de construção e realização social, a indiferença é a marca de um tempo que já não reconhece sua responsabilidade com o mundo, relacionando-se de forma estéril com a cultura e suas manifestações do campo da ética, da estética, da política, da educação.

Para Adorno (2008, p. 32), o combate à indiferença relaciona-se ao cultivo da civilidade. O filósofo lembra como Goethe, nas viagens de Wilhelm Meister, apresentou a civilidade, relacionada "à renúncia, à desistência da proximidade plena, da paixão e da felicidade inteira". Entretanto, a civilidade não finda na assimilação da normatização social, o que resultaria, por si só, em heteronomia. Ela atinge o indivíduo no que possui de mais íntimo, silenciando, "oportunamente", seu potencial ofensivo diante do outro e, assim, zelando para que a comunicação entre os homens se ajuste aos padrões amplos de hierarquia (relações de poder). Ainda que Goethe tenha apontado a civilidade como uma "referência salvadora entre os homens alienados" (ADORNO, 2008, p. 32) e que, atualmente, isso possa ser considerado como uma postura superada, Adorno nos instiga a pensar se construímos outro mecanismo de convivência social suportável, capaz de preservar, no mínimo a camaradagem (o ato de pedir desculpa, licença ou agradecer, por exemplo). Assim, a civilidade cria condições para o exercício da humanidade, numa relação de autonomia e de preocupação com o que o outro pensa e anseia. A partir das ponderações de Adorno, Cohn (2004, p. 84) articula as ideias de civilidade e formação como constitutivas de uma postura de responsabilidade (cuidado com o outro), contraposta, pois, à barbárie:

Civilização e cultura são dimensões inseparáveis do processo histórico, como figuras do universal e do particular. Trata-se de encontrar os elos entre ambas, não de identificá-las ou contrapô-las. Na dimensão da civilização o elo é dado pela civilidade; na dimensão da cultura, pela formação. Em ambos os casos, trata-se de imprimir forma à experiência: forma social num caso, forma significativa, no outro.

Nesse sentido, é possível a viabilização da solidariedade (e não a arbitrariedade); do pensamento crítico (e não a irracionalidade). Segundo Mate (2008, p. 118), a memória é elemento sempre pertinente quando sentimos a necessidade de reorientar o pensamento e a ação, por isso é chave do potencial intelectivo e não uma atividade espontânea ou aleatória. Nas sociedades contemporâneas, os campos da política e da ciência muito contribuíram para evidenciar os abusos da memória, distendendo seu aspecto supressivo, enquanto esquecimento, e rechaçando seu viés histórico-cultural, como conservação. Para Todorov (2000), esquecimento e conservação são movimentos imanentes, cuja interação contribui para a integridade física e mental do homem. Por isso, Nietzsche $(2009$, p. 73) dizia que "é absolutamente impossível viver sem esquecimento". No entanto, feito em nome do poder ou do progresso, esse processo seletivo pode distorcer a tarefa da memória, isolando-a e gerando, em diferentes níveis, violência, trauma, barbárie. Assim ocorreu na instalação de diferentes regimes 
totalitários, na China comunista, na antiga União Soviética e no Terceiro Reich, cuja história, conforme indica Primo Levi (1990), poderia ser relida como uma "guerra contra a memória". ${ }^{5}$

Certamente, a lembrança das atrocidades cometidas contra a humanidade - seja na forma de opressão, torturas, genocídios, catástrofes acidentais ou provocadas - é ainda uma tentativa válida para que não mais se repitam. Nesse sentido, apontar os horrores cometidos pelo nazismo produz, em muitos de nós, um efeito de alerta e resistência. Ademais, para além desse movimento de sensibilização, a atipicidade, sempre lembrada, desse extermínio precisa relacionar-se às causas mais profundas e humanas que ainda persistem na atualidade, pontuando a barbárie interior capaz de gerar desde movimentos fundamentalistas até manifestações cotidianas de homofobia, xenofobia, racismo e tantos outros preconceitos delirantes cometidos todos os dias. Jean-François Mattéi (2002, p. 12) afirma que, se levarmos em consideração grandes pensadores que já se dedicaram ao tema "barbárie" - Goethe, Schiller, Adorno, Castoriadis -, entendendo-a como "o colapso do humano e sua regressão a uma violência despida de significado, é no interior do homem que precisamos detectar as tendências a cair na barbárie". Por isso, a urgência de uma linguagem que não apenas compreende o passado, mas alimenta uma disposição ética frente ao outro é, pois, tarefa da formação e da produção do conhecimento.

Também podem acontecer distorções nas tentativas de elaborar uma trajetória contínua para a narrativa da memória, promovendo, com o passar do tempo, a incorporação de aspectos obscuros e/ou indizíveis da produção da cultura como acontecimentos factuais. ${ }^{6}$ Para Ricoeur (2000, p. 6), as narrativas podem guardar uma "irracionalidade identitária" no confronto ameaçador em relação ao outro, pois "além da sua amplitude no espaço e no tempo, a história fornece o estímulo da comparação, por meio da qual somos convidados a reinterpretar a nossa identidade como diferença em relação às identidades adversas". A memória pode provocar a tendência a uma ameaça e deposição do outro, pois "são realmente as humilhações, os danos reais e imaginários à estima de si, sob os golpes sofridos por uma alteridade mal tolerada, que transformam a relação que o mesmo mantém com o outro, levando-a do acolhimento à rejeição e à exclusão" (RICOEUR, 2000, p. 4).

Assim como a memória é uma dinâmica interativa infindável e permanente para o sentido histórico como construção humana no tempo, a alteridade é abertura à presença incômoda, é reconhecimento na polidez das relações não violentas (equiparadas ao conceito de dever) que abrigam o humano como construção e reconhecimento do outro. A auto-

5 E mais, tendo em vista as atrocidades pelos nazistas, o receio de Levi era de que a memória do extermínio fosse desacreditada. Os próprios alemães tinham essa noção e proclamavam: “'Seja qual for o fim dessa guerra, a guerra contra vocês nós ganhamos; ninguém restará para dar testemunho, mas, mesmo que alguém escape, o mundo não lhe dará crédito'. Talvez haja suspeitas, discussões, investigações de historiadores, mas não haverá certezas, porque destruiremos as provas junto com vocês. E ainda que fiquem algumas provas e sobreviva alguém, as pessoas dirão que os fatos narrados são tão monstruosos que não merecem confiança: dirão que são exageros da propaganda aliada e acreditarão em nós, que negaremos tudo, e não em vocês. Nós é que ditaremos a história dos Lagers" (LÉVI, 1990, p. 9).

6 Nesse sentido, podemos lembrar que a história amplamente sabida sobre quem inventou a lâmpada aponta a autoria para Thomas Edison quando, na verdade, ele patenteou e financiou a criação de Nikola Tesla, que não teve o reconhecimento de sua genialidade e legado na época. 
consciência, como presença crítica, é intersubjetividade vital que ajuda a viver e alimenta o reconhecimento dos distintos. Diante disso, Ricoeur tece duras críticas à perspectiva hegeliana de que o reconhecimento deriva da luta, do conflito e negação do outro decorrente do desequilíbrio social. Para o filósofo, a relação é efetivação do encontro de alteridades recíprocas no processo temporal e incerto da lembrança e do esquecimento, que diz um pouco das marcas do reconhecimento humano. A permanência incita a memória e a continuidade da existência, mas ao mesmo tempo faz que as certezas se tornem frágeis diante da diversidade. "[...] A questão do significado da identidade não é fácil neste sentido em que pelo menos, à primeira vista, a memória poderá ser uma identidade não apenas pessoal mas íntima: recordar-se é, ao mesmo tempo, recordar-se de si” (RICOEUR, 2000, p. 1).

A memória vai além de uma rememoração pessoal e privada pois é, igualmente, memória partilhada, coletiva, que envolve histórias da infầncia, de povos, de rituais festivos, de tragédias e de comemorações que são parte da construção social e associada à vida dos outros. Também não pode ser confundida com a memorização, que tenta conservar o passado sem exercitar uma seleção ético-estética dos acontecimentos - considerando, inclusive, o direito ao esquecimento de eventos (efêmeros ou dolorosos, por exemplo) -, mas visar à constituição de uma história universalizante, irrefutável. Essa propensão insiste em tornar fugazes as lembranças dos vencidos e vivaz o discurso dos vencedores. Tendo em vista que a memória e os movimentos de construção de trajetórias históricas são frutos de processos de escolha, de valoração de algumas experiências em detrimento de outras, observa Walter Benjamin (2012, p. 245):

Nunca houve um monumento da cultura que não fosse também um monumento
da barbárie. E, assim como a cultura não é isenta de barbárie, não o é, tampou-
co, o processo de transmissão da cultura. Por isso, na medida do possível, o
materialista histórico se desvia dela. Considera sua tarefa escovar a história a
contrapelo.

A construção de uma historicidade por meio da linguagem capaz de sensibilizar subjetividades, ao mesmo tempo em que produz um sentido comum, é condição importante para perceber as barbáries dos regimes totalitários, assim como as opressões praticadas em nome de uma suposta democracia. Afora a frequência, o interesse por fatos que envolvem atentados à vida, divulgados pela mídia, parece suprir a necessidade de relações humanizadas. Ora, admitir que os sujeitos plenos de sentido já não precisam do outro é esgotar as próprias possibilidades de humanizar-se, de formar-se pela abertura à alteridade. Assim, a indiferença é o esgotamento da humanidade, visto que não nascemos prontos e o movimento de devir nos mostra isso a cada instante. Conforme Ricoeur (2000, p. 7):

Devemos pelo menos saber porque é que protestamos e militamos. É em nome da ideia de dignidade de todo o ser humano, mesmo culpado; do seu direito a consideração. Porque, por trás do fazer sofrer esconde-se uma humilhação que gostaria que o outro perseguido perdesse o respeito por si e se desprezasse. 
O desafio maior está ligado à urgência do sujeito reconhecer o seu valor e responsabilidade pela humanidade, assumindo o respeito à vida e à dignidade humana como um projeto coletivo, intersubjetivo, no qual a construção do conhecimento vem acompanhada pelo reconhecimento ético. $\mathrm{O}$ ato de reconhecer o outro lhe retira de sua condição de objeto de conhecimento para torná-lo um ser com potencialidade criativa, crítica e valorativa com status ético distinto.

\section{O VALOR DO (RE)CONHECIMENTO NO MUNDO DESUMANIZADO}

Para aprendermos a ver o outro na sua dimensão de potência e diferença, é preciso deixar de lado os preconceitos, que transformam distinção em hierarquias a partir de crenças ilusórias, ou seja, formas de vida irracionais e contraditórias. Nas palavras de Honneth (2003, p. 219), "[...] com a experiência do rebaixamento e da humilhação social, os seres humanos são ameaçados em sua identidade da mesma maneira que o são em sua vida física com o sofrimento de doenças". A violência se opõe à ética porque trata seres racionais, políticos e sensíveis, dotados de linguagem e liberdade, como se fossem coisas, isto é, irracionais, insensíveis, mudos, inertes ou passivos. A indiferença é exatamente o limite da racionalidade, como sua destruição e inviabilização, como destituição dos humanos de sua condição de dignidade. A indiferença frente a uma opinião alheia, por exemplo, dispensa a necessidade da tolerância, pois esta significa a aceitação de pretensões de validade diferentes em relação a visões de mundo e implica o reconhecimento das mesmas. O agir comunicativo mede-se pelo reconhecimento intersubjetivo do acordo com os outros, sempre aberto à crítica.-

Todas as expressões linguísticas concretas de nosso existir estão envolvidas com uma significação conceitual e com uma apreciação valorativa humana, que supõe uma constituição renovada do saber. Aprendemos por meio de uma infinidade de problemáticas que remetem à educação como o campo de indeterminação humana, pois nem sempre precisamos confiar antropologicamente em nossas tradições (HABERMAS, 1987). Nessa perspectiva, podemos entender um projeto educativo como uma construção de caráter contrafático, que só faz sentido na presença do outro e precisa recusar qualquer tentativa de definição $a$ priori de seus conteúdos, para evitar abstrações descoladas das experiências. O racional tem como potencialidade as referências mútuas, que são formas de regulação das nossas relações intersubjetivas em sociedade. Para Jürgen Habermas (1997), os direitos são legitimados por um processo de politicidade e socialidade que preserva uma tensão entre a faticidade e a validade do direito mediante uma reconstrução pela racionalidade dos argumentos, que abre e renova infinitas possibilidades de relações com o mundo.

Diante disso, Habermas examina criticamente as legitimações desse entendimento positivo do saber no confronto com o mundo da vida, configurado pelo interesse humano e pelas condições históricas e sociais, a fim de guiar a constituição do conhecimento na relação com as diferentes atividades humanas estruturadas como linguagem. Partindo desse 
entendimento, o saber humano se constitui em três interesses que são produtos das preocupações cotidianas, a saber: o técnico - conhecimento que controla os objetos naturais (a racionalidade instrumental), o prático - conhecimento do entendimento interpretativo (informa e guia juízos práticos) e o emancipatório - conhecimento intelectual que visa à comunicação e à interação não alienada (HABERMAS, 1987).

As fronteiras que muitas vezes separam o que é humano (em termos de conhecimento e autorreflexão) do desumano giram em torno de nossas ações na interdependência humana, que são frutos da estreita relação com os processos de democracia e seus mecanismos sociais, políticos e culturais distorcidos ou reprimidos de comunicação e entendimento pelas compulsões irracionais (ideologicamente contaminadas). A convivência social depende do agir racional enquanto uma correta interpretação de si mesmo e de seus atos, que permite a reconstrução crítica das possibilidades e desejos de emancipação suprimidos (interesse na discussão racional, democrática e igualitária). A compreensão do significado e do valor que temos no contexto cultural nos habilita para a convivência humana como uma forma de vida que nos leva à competência comunicativa situada na ética da autorrealização, que transfere a fonte das ideias e conhecimentos humanos à linguagem e ao discurso. Por meio de nossas próprias ações na experiência vivida com a alteridade, aprendemos que, na base da sensibilidade e dos sentimentos, podemos decidir o que pretendemos ser e fazer. Assim, a nossa indeterminação ontológica e nossa liberdade dependem da convivência com os outros em nosso existir como humanos. Nesse processo, constituímos e configuramos nossa capacidade de sentir, ver, acolher, estabelecer relações, escolher e agir, realizando o projeto de construção de nós mesmos no cotidiano intersubjetivo.

A teoria do reconhecimento intersubjetivo desenvolvida por Axel Honneth (2003, p. 159-224) é estruturada teleologicamente em três diferentes padrões de reconhecimento: o amor (pressupõe o reconhecimento do outro pelos laços emocionais de relações primárias - ser que reconhece e confia no outro e que é simultaneamente autoconfiante e estranho), o direito (igualdade formal, autonomia jurídica e pretensões próprias na ação de reconhecimento mútuo) e a solidariedade (contribuição da particularidade de cada um no compartilhamento de valores éticos comuns). $\mathrm{O}$ ato de reconhecimento afetivo é fundamental para a constituição da identidade e personalidade, pois por intermédio do reconhecimento refletido e carente da presença do outro nos diferenciamos, estranhamos, singularizamos, e por isso nos qualificamos na tensão dessa relação conflitiva, aprendendo a nos diferenciar e a nos perceber autonomamente. $\mathrm{O}$ ato de reconhecer e ser reconhecido torna-se possível quando respeitados os três aspectos relacionais de reconhecimento intersubjetivo para que a dimensão da integridade pessoal e autorrealização humana sejam desenvolvidas e asseguradas por normas universais orientadoras da ação.

O campo da educação, por ser reconhecidamente uma prática humana, social e política, requer um envolvimento ativo dos sujeitos, enquanto prática vital potencializadora de interação e (re)construção dos conhecimentos. Por tudo isso, é uma das artes mais difíceis, pois está justificada no trabalho de pensar, que dá voz ao outro e transforma, ao mesmo tempo, as individualidades e a práxis social. No contemporâneo, a educação e a prática for- 
mativa também sofrem os efeitos da barbarização das relações. As condutas de civilidade que permitiriam aos sujeitos construírem uma experiência mais autônoma e diversa com o mundo foram, de alguma forma, tomadas pela instrumentalização e pela dessensibilização, o que interfere diretamente nos processos formativos. Segundo Adorno (2008), a supressão de uma postura caricaturada de civilidade, entendida, então, como expressão de humanidade e autonomia seria condição para a convivência social suportável. Diferente disso, a indiferença como manifestação de barbárie continua permeando as relações e nublando o reconhecimento mútuo. Sobre o contexto atual da educação, Flickinger (2011, p. 10) afirma:

\begin{abstract}
Além disso, as últimas preocupações com a dependência desastrosa que a origem social dos educandos exerce sobre suas chances de formação, também vêm confirmando a importância de um reconhecimento social capaz de trabalhar as diferenças sociais e culturais. Teríamos de falar também da negligência das questões do reconhecimento social perante o peso maior dos conhecimentos, em detrimento das experiências intersubjetivas; fato este que me faz acreditar que aí se esconde um dos motivos do crescimento da violência social.
\end{abstract}

A postura da responsabilidade pelo mundo constitui, pois, uma possibilidade de superar as tensões causadas pelas indiferenças (da racionalidade estratégica, do preconceito, da incomunicabilidade), cedendo lugar à empatia, ao reconhecimento do outro e à consideração das experiências vividas. Por isso, nos moldes democráticos, a educação que se projeta pelo caráter expressivo da construção do conhecimento só pode mediá-lo a partir da instância intersubjetiva, ou seja, considerando as relações culturais tecidas e compartilhadas. Reconhecer o outro na complexidade da prática formativa envolve, assim, colaboração, tensão criativa, desestabilizando posições dogmáticas e hostis, para estabelecer relações guiadas e comprometidas com a pluralidade.

A partir da perspectiva habermasiana, entendemos que o convívio com a diversidade indica a necessidade de projetar um caminho do que seria o intolerável, visto que não há inclusão sem exclusão, assim como não há determinações sem problemas ou distribuições desiguais de dificuldade. Uma formulação aceita por todos sugere o reconhecimento recíproco e implica a ligação entre tolerância e democracia, pois a identidade humana só pode se formar com base na reprodução, revisão e renovação cultural (HABERMAS, 2005). A tolerância exige a necessidade de rejeitar e neutralizar um preconceito, pressupondo possíveis desacordos. Por isso, o ambiente educativo é um espaço propício à reversibilidade, ou seja, para se autoconhecer e se reconhecer no outro, desenvolvendo o sentimento da empatia no movimento de falar e ouvir a narrativa dos outros para aprender a colocar-se no lugar do outro. A educação consiste justamente no reaprender com o outro e, por isso, não pode ser indiferente aos participantes envolvidos no processo, pois seu sentido está vinculado ao compromisso com a vida, que envolve a compreensão e a comunicação.

Se bem entendemos, a assunção da tarefa mediadora da educação no processo de formação humana e responsabilidade pela vida se efetiva por meio do reconhecimento de múltiplas racionalidades. Tais racionalidades abrangem não apenas a cognição, mas 
também vontade, desejo, gosto e afetos, misturados na subjetividade e desenvolvidos na intersubjetividade (HABERMAS, 1987). Tudo isso comporta o processo formativo, desde condições de civilidade favoráveis à percepção e à expressão até exercícios de pensamento e ensaios miméticos na cultura, visando às possibilidades de articulação entre conhecimento e reconhecimento.

\section{CONSIDERaÇões Finais}

Sob a lógica da diferença, da sensibilidade e da pluralidade do saber, a inconclusão humana atesta nossa ignorância e abre perspectivas para conhecer a si e aos outros. Nesse sentido, pensar a alteridade como solicitude implica adotar uma postura de responsabilização pelo próprio processo de busca e construção do conhecimento. Afinal, a implicação no processo formativo só pode ocorrer na expressividade da articulação entre subjetividade e intersubjetividade. Por isso, também, o conhecimento não é a posse de um saber, mas um processo de construção solidária e colaborativa mediante o respeito a si mesmo e aos outros interlocutores.

Talvez, nessa perspectiva, podemos retomar a problemática inicial deste ensaio, pois as possibilidades de formação e de posicionamentos éticos frente à indiferença se erigem de uma necessária revisão, no contemporâneo, sobre o valor da interação e da memória na constituição da humanidade. A regressão do humano ao descaso e à violência gratuita são efeitos, mas também causas, de uma desrazão social, que não consegue perceber nas narrativas da cultura justificativas para compor relações éticas no cotidiano. $\mathrm{O}$ enfrentamento dessa forma de barbárie, a indiferença, dá-se tanto no âmbito jurídico, preservando as condições de igualdade e respeito pela singularidade, quanto formativo, revitalizando as práticas culturais que abrigam os sentidos de nossa presença no mundo e reconstruindo formas de pertencimento e implicação com a alteridade.

Certamente, porque há a incerteza e a necessidade de reconhecimento de diferenças que a educação se torna pensável na realidade contemporânea, uma vez que a transformação operada pela linguagem tem na reivindicação do aprendizado social a abertura à conversação como potencial de alteridade. Na experiência formativa, há uma abertura para a reinvenção das relações comunicativas com os outros, geradoras de conhecimento e reconhecimento. Nesses termos, qualquer ato criativo é sempre revolucionário e formativo, pois visa à alteração, à mudança da realidade na práxis do agir humano responsável. A arte de educar é esse esforço constante e hermenêutico de autointerpretação da expressão humana, que sensibiliza os conceitos, criando condições para aprender, agir e interagir. Isto porque é sempre produzida com o outro, aprendida cooperativamente e vivida como disposição de sentido pedagógico.

Se ainda vivenciamos uma educação abstrata, explicadora (técnica de escravização mental que formaliza hábitos simplificadores do pensar), de hierarquização dos conhecimentos, estamos contribuindo para a reprodução da indiferença. Ao contrário disso, a ação 
que tem como horizonte uma ética da solicitude não deixa de se afetar com a diversidade, num sentido formativo, de conhecer e reconhecer a capacidade de decisão e cooperação do/ com o outro, preservando os direitos mais fundamentais da vida e da dignidade humana.

\section{REFERÊNCIAS}

ADORNO, T. W. Educação e emancipação, 2. ed. Rio de Janeiro: Paz e Terra, 2000.

ADORNO, T. W. Minima Moralia: reflexões a partir da vida lesada. Trad. Gabriel Cohn. Rio de Janeiro: Beco do Azougue, 2008.

ARENDT, H. A condição humana. Trad. R. Raposo, 9. ed. Rio de Janeiro: Forense Universitária, 1999.

BENJAMIN, W. Sobre o conceito da história. In: BENJAMIN, W. Magia e Técnica, Arte e Política. Trad. Sérgio Paulo Rouanet, 8. ed. São Paulo: Brasiliense, p. 241-252, 2012.

COHN, G. Indiferença, nova forma de barbárie. In: NOVAES, A. (Org.). Civilização e barbárie. São Paulo: Companhia das Letras, p. 81-89, 2004.

FLICKINGER, H.-G. Autonomia e reconhecimento: dois conceitos-chave na formação. Educação, 34 (1), p. 7-12, 2011.

GADAMER, H.-G. Verdade e Método I: traços fundamentais de uma hermenêutica filosófica, 3. ed. Trad. Flávio Paulo Meurer. Petrópolis: Vozes, 1999.

HABERMAS, J. Teoría de la Acción Comunicativa I: Racionalidad de la Acción y Racionalización Social. Madrid: Taurus, 1987.

HABERMAS, J. Direito e democracia: entre faticidade e validade. Trad. Flávio Beno Siebeneichler. Rio de Janeiro: Tempo Brasileiro, 1997.

HABERMAS, J. Agir Comunicativo e Razão Destranscendentalizada. Trad. Lucia Aragão. Rio de Janeiro: Tempo Brasileiro, 2002.

HABERMAS, J. Intolerance and discrimination. Revista internacional de direito constitucional, 27 (1), p. 2-12, 2005.

HERMANN, N. A questão do outro e o diálogo. Revista Brasileira de Educação, 19 (5), 477-493, 2014.

HONNETH, A. Luta por reconhecimento. A gramática moral dos conflitos sociais. São Paulo: 34, 2003.

LÉVI, P. Os afogados e os sobreviventes. Trad. Luiz Sérgio Henriques. Rio de Janeiro: Paz e Terra, 1990.

MATE, R. La herencia del olvido. Madrid: Errata Naturae, 2008. 
MATTÉI, J.-F. A barbárie interior: ensaio sobre o i-mundo moderno. Trad. Isabel Maria Loureiro. São Paulo: Editora UNESP, 2002.

NEGT, O.; KLUGE, A. O que há de político na política? Relações de medida em política. 15 propostas sobre a capacidade de discernimento. Trad. João Azenha Júnior. São Paulo: Fundação Editora da UNESP, 1999.

NIETZSCHE, F. Genealogia da moral. Trad. Antônio Carlos Braga. São Paulo: Escala, 2009.

RICOEUR, P. Identidade frágil: respeito pelo outro e identidade cultural. In: Congresso da Federação Internacional da Acção dos Cristãos para a Abolição da Tortura, 2000.

SOUZA, R. T. de. Ética, política e responsabilidade social: algumas reflexões introdutórias. In: BOMBASSARO, L. C.; KRÜGGELER, T.; SOUZA, R. T. de (Orgs.). Democracia e inclusão social: desigualdade como desafio para a sociedade e a igreja no Brasil. Bonn: KAAD. Porto Alegre: EDIPUCRS, p. 143-151, 2009.

TODOROV, T. Los abusos de la memoria. Trad. Miguel Salazar. Barcelona: Ediciones Paidós Ibérica, 2000.

Dados Autores:

Elaine Conte

Graduada em Pedagogia e Mestre em Educação pela Universidade Federal de Santa Maria (UFSM). Doutora em Educação pela Universidade Federal do Rio Grande do Sul (UFRGS). Professora da Graduação em Pedagogia e pesquisadora do Programa de Pós-Graduação em Educação - PPGEDU/UNILASALLE. Líder do grupo NETE/CNPq.

\section{Maiane Hastchbach Ourique}

Doutorado em Educação (UFSM). Professora Adjunta da Universidade Federal do Pampa (UNIPAMPA).

Submetido em: 22/02/2017

Aceito em: 22/03/2018 